\title{
The Impact of Assisted Reproduction on Socio-Cultural Values and Social Norms
}

\author{
Steven R. Lindheim ${ }^{1 *}$, Kathryn Coyne ${ }^{1}$, Leslie Ayensu-Coker ${ }^{2}$, Kathleen 0'Leary ${ }^{3}$, \\ Stephanie Sinn", Ami S. Jaeger ${ }^{4}$ \\ ${ }^{1}$ Department of Obstetrics and Gynecology, Boonshoft School of Medicine, Wright State University, \\ Dayton, USA \\ ${ }^{2}$ Division of Pediatric \& Adolescent Gynecology, Cincinnati Children's Hospital Medical Center, Department of \\ Obstetrics \& Gynecology, Cincinnati, USA \\ ${ }^{3}$ Wright-Patterson USAF Medical Center, Dayton, USA \\ ${ }^{4}$ Arizona Reproductive Institute, Tucson, USA \\ ${ }^{5}$ BioLaw Ethics Institute, Santa Fe, USA \\ Email: * steven.lindheim@wright.edu
}

Received 26 September 2014; revised 25 October 2014; accepted 23 November 2014

Copyright (C) 2014 by authors and Scientific Research Publishing Inc.

This work is licensed under the Creative Commons Attribution International License (CC BY).

http://creativecommons.org/licenses/by/4.0/

(c) (i) Open Access

\begin{abstract}
Since the birth of the first "test tube" baby, the use of in vitro fertilization (IVF) has undergone an enormous metamorphosis. Initially designed for blocked fallopian tubes, IVF has found a number of other clinical applications over the past 40 years. However, as the science has advanced, traditional norms of conception and parenthood have been challenged and reproductive health ethics, guidelines, and law struggle to keep pace. Controversies and debates have arisen within the law, public policy, and the meaning of family across societies and religious sects. This paper will highlight some of the current and complex social, moral, and legal questions surrounding the implementation and advancement of assisted reproduction including Cross Border Reproductive Care, Oocyte Donation and Consents, Oncofertility, Posthumous Reproduction raising fresh discussion and debate.
\end{abstract}

\section{Keywords}

Assisted Reproductive Technology, Cross Border Reproductive Care, Oocyte Donation, Fertility Preservation, Fertility Insurance

\footnotetext{
${ }^{*}$ Corresponding author.
} 


\section{Introduction}

Since the work of Robert Edwards and Patrick Steptoe, whose efforts resulted in the first "test tube" baby in July 1978 (Steptoe \& Edwards, 1978), more than four million babies have been born through the use of in vitro fertilization (IVF) techniques. In the United States, slightly more than $1 \%$ of all neonates are conceived using IVF. This is in contrast to several countries in Europe where the use of assisted reproductive technology is more common, with a range of 3\% - 5\% (Jones, 2011). In Denmark, for example, in 2007, 5\% of all births were attributed to IVF, while in Australia it is close to 3\%.

Assisted reproduction has undergone an enormous metamorphosis. Procedures using rabbit embryos and transfers were first reported in 1891 (Heape, 1891), and continued to advance resulting in the first birth of newborn rabbits from IVF by George Pincusinin the 1930s. It wasn't until the 1940s, though, that John Rock and Miriam Menkin partnered to fertilize the first in-vitro human oocyte (Rock \& Menkin, 1944). Their work received public attention during the World War II; however, resistance from the Catholic Church played a role in impeding progress in the development of human embryos (McLaughlin, 1982). Interest in human IVF resurged in the 1960s largely due to the work of Robert Edwards and Patrick Steptoe, which paved the way for the birth of the first "test-tube” baby in 1978 (Edwards, 1965; Edwards, 1969; Edwards, 1970; Steptoe, 1970).

Early European advances in IVF were not embraced in the U.S. This occurred in part because the pronouncements were sensationalized by the Catholic Church, U.S. media and scientific press. The announcements of the discoveries were contextualized by eugenic experiences and concerns both in the U.S. and Europe. John Rock's groundbreaking work was criticized, but when the work of Edwards and Steptoe was announced, the criticism was magnified. Funding by the NIH was halted until it was deemed ethically acceptable for the federal government to support work on IVF (Biggers, 2013). Eventually, the Ethics Board convened during the Carter Administration recommended that any experiment utilizing spermatozoa and oocytes should be donated from a married couple, though this recommendation was never officially accepted (Biggers, 1978; Biggers, 1981).

While there were detractors attempting to limit IVF, infertile couples and the medical community continued their work. Despite the public banter that gave a strong voice to IVF opposition, two retired doctors from Johns Hopkins, Drs. Howard and Georgeanna Jones, opened an IVF clinic in March of 1980 under the guidance and suggestions of Dr. Edwards. Their conviction and collaboration resulted in the birth of Elizabeth Carr to Judy and Rodger Carr on December 28, 1981. Due to the concern for negative press and invasion of privacy, it was decided to keep Judy's identity confidential. She remained in Norfolk for the last month of her pregnancy under an assumed name. During the pregnancy, ultrasounds suggested the infant's head was small, which is a sign of intrauterine growth restriction or birth defects. This created anxiety for both the family and the doctors. They worried that if the first IVF baby was born with malformations, the backlash would be fierce, creating ammunition for the many critics who considered IVF unnatural and immoral. Although they were prepared to address and discuss any adverse outcomes, the projections were incorrect and Elizabeth was born healthy.

IVF was initially designed for the treatment of blocked oviducts, which physicians knew resulted in sterility by the middle of the $19^{\text {th }}$ century (Churchill, 1846). While surgical therapies were attempted, most were fraught with dismal outcomes. IVF has helped overcome the poor surgical outcomes. Today, IVF is also used to treat male factors, endometriosis, recurrent pregnancy loss, and unexplained infertility. IVF outcomes have also significantly improved over the past 30 years due to improvements in the use of controlled ovarian hyperstimulation, improved embryologic technology, intracytoplasmic sperm injection (ICSI), cryopreservation, embryo transfer technique, the acceptance of donor eggs and sperm, and gestational surrogacy.

Involvement of donors took IVF on an unexpected turn. While the advent of assisted reproductive technology came about through the clandestine use of donated sperm almost a century ago (Henig, 2004), the use of donated oocytes was first described in 1983. This technology was used as a means to establish pregnancy in a patient with primary ovarian failure (Trounson et al., 1983; Buster et al., 1983). Now more than 30 years later, the use of donated oocytes, sperm and embryos has increasingly become routine for IVF clinics. Donations account for almost $14 \%$ of all in vitro fertilization cycles in the United States reported in the Society for Assisted Reproductive Technology (SART) and Centers for Disease Control and Prevention ART/CDC registry (SART 2012). Through the landmark efforts of the groups at Monash University and the University of California, Los Angeles (Lutjen et al., 1984; Bustillo et al., 1984) this technology has resulted in more than 50,000 births over the last 30 years in the United States alone.

The involvement of donors has gained increasing acceptance among patients and now plays a major role in 
treating intractable problems related to oocyte function. In 1992, oocyte donation was successfully extended to women after the age of 50 (Sauer et al., 1993), revealing that women of any age could theoretically become pregnant. At the same time this collectively created public debate and spurred sensational commentaries and moral concerns for donors, who are healthy women being paid to undergo medically dangerous procedures that may damage their ability to have children. The moral debate has somewhat subsided, though, and currently most feel that human oocyte, sperm and embryo donation is ethically and socially acceptable. The medical risks to the egg donors are also better understood and managed.

In the past 10 years, a new area of assisted reproduction has emerged called oncofertility. Fertility preservation has developed as a discipline dedicated to conserving the reproductive potential of cancer survivors. Cryopreservation refers to the cooling of cells and tissues in order to preserve them for future use, and since the 1990s, embryo cryopreservation has become useful in both optimizing IVF success rates and allowing for fertility preservation. Cancer rates in men and women of reproductive age have continued to increase in recent years and given the advances in cancer therapy, it has dramatically decreased the mortality rates. Since 1990, the prevalence of cancer survivors in young adults increased from 1 in 1000 to 1 in 250 patients (American Cancer Society, 2010) due to more aggressive therapies. Current cancer therapies may have profound toxic effects on gamete function with infertility as an expected consequence (Lee, 2006), and approximately $90 \%$ of men and women diagnosed with cancer may be at risk of permanent infertility (Wallace, 2005; Sommezer, 2006).

Significant progress in the advancement of fertility preservation therapies and a heightened awareness of the availability of therapies has occurred and is formally recognized by the American Society of Clinical Oncology (ASCO) and the American Society of Reproductive Medicine (ASRM). Guidelines from these organizations recommend that all newly diagnosed cancer patients of childbearing age be informed about potential loss of fertility and receive referrals to infertility specialists as appropriate (ASRM, 2005; Lee, 2005). Gamete preservation including semen, oocyte, and embryo cryopreservation has become standard therapy, significantly increasing the options available to patients. Given the time-sensitive nature of providing fertility preservation therapies, collaboration among the oncologist, gynecologist, and reproductive specialist is critical to ensure prompt utilization of these therapies, but often pose interesting and challenging issues (Practice Committee of ASRM, 2013).

Providing options for preserving fertility in men, women, and even children is an important reproductive health issue. Fertility preservation counseling is a complex process, and there remain significant considerations including social, ethical, and legal attitudes that require awareness and sensitivity. Receiving a diagnosis of cancer, facing a prognosis and determining a treatment course are overwhelming for the patient. In short order, a "Pandora's box" of emotions is released, and many decisions must be made quickly within the context of social norms and taboos, including religious-cultural-ethical values, access to care and cost of services, developmental capacity and consent, posthumous reproduction and postmortem parenting.

As assisted reproduction continues to expand and change, the field challenges the traditional norms of conception and parenthood. This review could not cover many of the controversies that have been raised. For example, one area of debate is whether having children is a right, and another is whether societies should support and fund procreation. Other issues include discarding "normal embryos" and the purposeful creation of an abnormal embryo. Each concern raises many controversies and has created debate with the law, public policy, and the meaning of family across societies and religious sects where very strong moral beliefs greatly differ. This paper will focus on some of the more recent and evolving issues confronting us that are leading to broader social and legal questions.

\section{Cross Border Reproductive Care}

Cross-Border Reproductive Care (CBRC) is a growing phenomenon in which infertile patients cross borders from their country of residence to another in order to receive specific reproductive treatments not allowed or not available in their own country (Pennings, 2004). It was originally coined "procreative tourism" (Knoppers \& Le Bris, 1991), and also referred to as "fertility tourism" and "reproductive tourism." Some have argued that this term is both inaccurate and inappropriate as it suggests that couples are travelling for pleasure when reproductive care may instead be challenging, time-consuming, frustrating, and impoverishing (Inhorn \& Patrizio, 2009). The term "reproductive exile" has been suggested as it implies that one leaves the country not just for political reasons, but for access to medical treatment prohibited by the law (Matorras, 2005). The more neutral term that is favored by European Society for Human Reproduction and Embryology (ESHRE) and ASRM is Cross Bor- 
der Reproductive Care, as it avoids connotations of pleasure and leisure time and places no value judgment regarding movement for reproductive care (Shenfield, 2010, 2013).

CBRC represents the convergence of commerce, medicine, and travel, and is currently promoted as such by national governments in some countries including India and Thailand (Whittaker, 2010; Crooks, 2011; Qadeer, 2010). The main reasons for CBRC include: 1) treatment is prohibited in the country of origin because the application is considered ethically unacceptable (use of donor gametes or sex selection for non-medical reasons, etc.); 2) patients possess characteristics that are considered to make them unfit for parenthood (postmenopausal or lesbian, etc.); 3) the technique is considered medically unsafe (oocyte freezing, cytoplasmic transfer, etc.); 4) treatment is not available because of lack of expertise (preimplantation genetic diagnosis); 5) the waiting lists are too long (donor oocytes); or 6) costs (fees) are exorbitantly high, removing treatment from financial reach (Pennings, 2004). In essence, CBRC has existed from the moment of inception of the first IVF cycles in England in the 1970's, but has grown dramatically and emerged as a globalindustry. This has occurred particularly in the last ten years with the aid of commercial infrastructures, such as global hubs, intermediaries, news media, and new spaces of interaction including the Internet and blogs designed to support CBRC and inform patients (Inhorn, 2011; Pande, 2011).

From a human side, these aspects of securing care have been referred to as "push and pull factors". Patients are being pushed abroad for reproductive care. The "pull factors" are where patients must evaluate and decide where and which fertility program to seek for care. The Internet has allowed patients to perform endless searches for the optimal clinic, join blogs and supports groups and identify specialized broker groups (Blyth, 2010). Patients have chosen a specific country based on religious identity, the comfort of shared language, absence of discrimination, or were expatriates returning home for medical care (Inhorn, 2012). Infertility clinics also have an interest in pulling patients into their clinic by advertising care at a lower cost, offering timely treatment, or promoting more favorable legal processes or laws that protect and recognize parental rights (Speier, 2011). Many times the reduced medical costs cover up the huge legal risks and costs that patients don't consider until it is too late. Thus the phenomenon of cross border reproductive care is made possible by globalization and commercialization of the technology of assisted reproduction.

Estimates on the prevalence of CBRC in Europe are derived from a 2010 survey which indicated that 4000 30,000 cycles of cross-border treatment are performed annually (Shenfield, 2010; Hudson, 2011), accounting for approximately 5\% of all European fertility care (De Mouzon, 2013). In the United States, survey data demonstrate that $4 \%$ or 6000 cycles annually of all fertility treatment is delivered to international patients who do not reside in the U.S. (Hudson, 2011).

In general, CBRC has some inherent benefits to patients including improved access, reduced cost, circumvention of legal restrictions or avoidance of discrimination, and protection of privacy for patients and their significant other. On the other hand, there are potential issues and harm for those utilizing CBRC. The biggest concern for patients traveling abroad is the risk they take regarding their health and safety where substandard practices could potentially lead to the transmission of infectious diseases. There is also potential for increased vulnerability when information about quality and treatment options is less accessible. This is understandable particularly when patients do not speak the native language in the destination country and is of significant importance when they financially commit to treatment. Another risk is lax or nonexistent professional safeguards and consumer protection laws. Sentinel examples include patients traveling to access donor eggs who are misled, either by coercion or omission, into utilizing a different gamete donor than the one the patient originally selected. This is termed the "bait and switch" scheme, and is typically discovered when the growing child bears no resemblance to the selected donor (Cohen, 2010).

Concerns and criticisms of CBRC focus on the exploitation of gamete donors in destination countries (ASRM, 2013; Storrow, 2006; Whittaker, 2010; Smith-Cavros). Potential for exploitation of donors is not limited to compensation. There is a potential for donors to take either uninformed or unnecessary health risks. A few examples include not waiting long enough between donations, creating complications for a donor without access to care, and challenging the donor's psychological views of mothering and parenting, which could impact her attitudes toward her future children.

To meet the demand for healthy, young donors, infertility clinics throughout the world balance the need for reasonable remuneration against the known risks of ovulation induction and oocyte retrieval (Leeton, 1993). In general, practitioners have justified payment by citing the complexity of the process, risks assumed, and time required of donors who must use parenteral drugs for ovarian hyperstimulation and undergo follicle aspiration 
and anesthesia to donate oocytes (Sauer, 1997). While guidelines for physicians to ensure ethical practice of CBRC exist (Shenfield, 2011), arguments against compensation for gamete donors hinge on the fact that payments of large sums of money lead to coercion and undue inducement.

Additionally, offspring who are the result of gamete donation abroad may have less access to information about their genetic origins than donor-conceived children produced by domestic arrangements (ASRM, 2013; Crozier, 2010). For patients who live in a country where identifiable donation is mandatory, by travelling to other countries where gamete donation is anonymous, they act against a social trend. In recent years, as the interest in knowing one's genetic origins has been elevated to meet the emotional needs of the child, challenges arise if the donor does not speak one's native language, comes from a different culture, and/or lives far away in another country.

From a medical perspective, other care issues may ensue for both donors and patients. Those utilizing CBRC may also be at increased risk for multiple pregnancy and the associated morbidity and mortality, which can have a significant impact on offspring health (McKelvey, 2009). Legal norms may also leave a patient without recourse for malpractice or personal injury. If a patient is harmed by treatment abroad, achievement of an injured patient's recovery from a negligent foreign provider may be exceedingly difficult due to medical malpractice laws and norms in the destination country (Cohen, 2010). Likewise, if a broker absconds with a patient's money, there may be no legal recourse to recoup the patient's funds.

Other ethical quandaries have also been raised and extensively reviewed (Inhorn, 2012; ASRM, 2013) from the perspective of the physician and the care given to those utilizing CBRC. These include the physician's duty to inform patients about the opportunities and risks-benefits of CBRC and the duty to resume care for patients who obtained CBRC even if she has little or no documentation of the care she received. Is it the physician's role to disclose of legal or practical information relating to the patient's return home? Should the physician be responsible for the difficult task of procuring immigration paperwork for donor-conceived offspring or report that the CBRC service is illegal in a patient's home country? (Gurtin, 2011).

CBRC has clearly changed the landscape for assisting patients in creating families, and most patients report high levels of satisfaction with CBRC and its outcomes. But where do we go from here? There are many issues to address: from evading the law, to religious bans, to accessing cost-effective higher quality of care, to creating an industry and accreditation standard. This is where international guidelines will need to be developed, if standardization becomes a global concern.

\section{It's All in the Wording-Do Patients Hear What We Say or Hear What They Want?}

During the last two decades, oocyte donation increasingly has been accepted as a method of assisting women without healthy oocytes to bear children. The pressure on infertility programs to provide third party oocyte donors has dramatically increased as the demand for oocyte donation throughout the world continues to escalate. This is a result of improved outcomes and greater social acceptance of the concept of oocyte donation. In the United States, the number of clinics performing oocyte donation has also risen. The majority of centers in North America offering this method of assisted reproduction now perform more than 15,000 cases per year, accounting for 12\% of in-vitro fertilization procedures in 2010 (CDC, ASRM, \& SART, 2012).

Following the lead of ASRM (ASRM Ethics Committee, 2007), compensation for oocyte donors is structured to acknowledge the time, inconvenience, and discomfort associated with screening, ovarian stimulation, and oocyte retrieval. Compensation should not vary according to the planned use of the oocytes, the number or quality of oocytes retrieved, the number or outcome of prior donation cycles, or the donor's ethnic or other personal characteristics. In the United Sates, total payments to donors in excess of $\$ 5000$ require justification and sums above $\$ 10,000$ are considered inappropriate. Yet surprisingly, couples may be willing to pay exorbitant amounts for a donor with "exceptional qualities", appealing to students desperately in need of money to pay bills and college loans (McGee, 1997).

Some have suggested that potential oocyte donor candidates are often misinformed about potential risks, or the risks of the donation process are misrepresented, especially by donor agencies (Gurmankin, 2001). There may be a tendency to minimize risks in order to recruit larger donor pools to accommodate waiting recipient couples. As a result, misinformed donors remain ignorant and may decide to donate when perhaps they would have decided not to proceed if given more complete information about the process. In another study, the authors 
reported that $8 \%$ of donor candidates declined further screening when informed of all the possible clinical scenarios for which their oocytes could be used. Approximately two-thirds of donor candidates reported ambivalence to proceed but did so trusting the infertility specialist in their screening process (Adsuar, 2005).

Disclosure is a key element in the informed consent process. Studies suggest that "low-balling" research candidates (i.e. not providing all information at the outset) or "anchoring" research candidates on initial information, resulting in failure to adjust sufficiently to information disclosed later ("under-adjustment”), may induce a candidate to make an initial commitment that she may regret later (Cialdini, 1978). Furthermore, research candidates subsequently given less desirable information about the process are less likely to withdraw from their agreement because of the psychological commitment or physical investment made. It has been suggested that potential oocyte donors are less likely to back out of donating after becoming fully informed of the process because of a reluctance to disappoint the program, agency or recipient once an initial investment has been made (Gurmankin, 2001; Cialdini, 1978). It is unclear if including a legal consultation to allow the donor to consider the process provides better information and ability to reflect on her participation and if it supports the donor to make a truly informed decision about whether or not to participate.

Traditionally, oocyte donor participation has been considered to be voluntary and typically altruistically motivated along the lines of helping childless couples. The escalation of payment reveals that money has become a dominant factor motivating interest. The "new age" donor appears less interested in the needs of the couple than her own employment by the program. This evolution in donor attitudes is not without negative ramifications, and fuels criticism by many both inside and outside the field of assisted reproduction. Concerns regarding the seductive nature of financial incentives are real, and young donors may be unable to adequately weigh the risks of oocyte donation against the benefits of such large monetary reward.

The obvious risks to the oocyte donor relate to the complications to ovarian hyperstimulation and oocyte retrieval. Less appreciated, however, are the issues regarding the execution of donor-recipient legal contracts. Legal contracts, recommended by ASRM, have increasingly become a central component of the oocyte donor and recipient process (ASRM, 2002). Legal agreements are used to outline and memorialize the duties and responsibilities of both the donor and recipient, and to clarify intentions of the parties regarding legal parentage. It is recommended that the legal consult be initiated early in the evaluation and screening process to ensure that the donor and the recipient expectations are allied. Surprisingly, reports suggest that more than $70 \%$ of donor-recipient contract terms are different from the discussions during the donors' initial medical encounter (Jaeger, 2012). It is unclear as to the reason for this, but donors may feel uncomfortable with the attorney's process to review the contract, or feel pressured to say "yes" and move the process forward in a timely way, and thus be making hasty decisions that they may later regret.

Another area of concern surrounding the informed consent process and the impact of "low-balling", "anchoring”, or "under-adjustment" can also be highlighted in the clinical genetics branch of medicine. As advances in molecular genetics continue to evolve, including the use of comparative genomic hybridization microarrays and other genomic technology such as high-density single nucleotide polymorphism (SNP) genotyping microarrays (Homer, 2008), researchers and clinicians will be able to further identify individuals who are genetically susceptible or at an increased risk for a particular disease. In some cases, obstetrical outcome may ultimately reveal a medical condition in a live born child that is attributed to the donor. Further genetic testing may be required and could have consequences including 1 ) re-contacting the donor at a later date for tissue typing; 2 ) request for organ donation or bone marrow transplant (Zilberstein, 1997); and 3) ethical quandary about disclosing information to the donor who may not want to know, or even disclosing to her spouse or family over her objections (Beskow, 2004).

Furthermore, advances in molecular genetics can lead to the molecular diagnosis and recognition of many genetic conditions from stored blood samples of gamete donors or cord blood samples in offspring. This may allow researchers and clinicians to recognize genetic profiles and identify certain treatable or preventable diseases in gamete donors and their offspring in the future that could make a donor uninsurable. The development of these new testing techniques, as well as the advancement of reproductive medicine, has progressed so swiftly that clinical and legal policies have struggled to integrate the informed consent, future re-contact, legal and psychological aspects of the testing modalities.

In light of these identified risks, the consent process needs to evolve from a one-time occurrence to a continuing process. Views change over time, especially when one has a chance to reflect on what they have done. It has been reported that oocyte recipients are generally amenable to disclosure to their oocyte donor regarding 
pregnancy outcome (88\%), contact for a medical emergency (74\%), and disclosure of medical or genetic condition (88\%), and this was consistent over time from the ante-to post-partum periods. Oocyte donors are also generally amenable to contact for a medical emergency (83\%) and disclosure of adverse medical or genetic outcomes (83\%); however, they were reticent to obtain the knowledge of pregnancy outcomes (31\%). Following oocyte retrieval, there is more general reticence to receiving information regarding a medical or genetic condition (93\% vs. 38\%). This highlights that the human condition is continuously evolving, and as medical, psychological, and legal counsel professionals, we need to take an integrative approach to optimize and support oocyte donors and recipients through this process. This is especially true in the assisted reproduction context, because the parties are coming together to create a new life, instead of consenting to a procedure to extend or improve an individual's health as is more typical with medical informed consent.

Informed consent is a complicated concept, which involves more than signing a form of authorization for a procedure in order to protect providers from legal risks. Creating a valid method of informed consent is paramount to the ethics of future identification and disclosure of individual genetic results or birth outcomes that could impact the individual or other donor family members. Informed consent must include future provisions for the identification of results and outcomes regarding the right to disclose genetic results, which needs to be clearly identified to truly respect a patient's future autonomy (Sleep, 1991; Spivey, 1991). This would assist in deciding the amount of information that needs to be disclosed to the patient in order for them to make a rational and educated decision and have complete understanding for autonomous consent.

While program resources and allocation of staff to address these issues are limited, all programs participating in gamete donation have an ethical obligation and a legal duty to understand, respect, and counsel all involved parties' disclosure desires through comprehensive informed consent and counseling processes. Egg donor programs, both in-house and agencies, should establish policies regarding disclosures and re-contact procedures. Programs should work closely and cooperatively with attorneys preparing donor-recipient agreements so that contract provisions match the desires of both parties and the policies and procedures of the program or agency.

\section{Religious Issues}

Many religions, such as Judaism, Christianity, Islam, Hinduism, and Buddhism, address bioethical concepts and play an active role in discussions concerning the use of assisted reproductive technologies. However, religious views may often conflict with available options for pregnancy prevention and procreation, particularly as advances in assisted reproduction continue to evolve and raise religious questions that may not have clear answers. Overall, views among the world's religions vary widely. Much more has been written on semen cryopreservation, but as oocyte, embryo and ovarian tissue cryopreservation continues to be utilized as a medical option, more involvement from the religious sector has come to the forefront. We will highlight some specifics related to semen cryopreservation as comprehensively reviewed elsewhere (Schenker, 1998; Banuaz-Zubair, 2007; Benagiano, 2008; Grazi, 2008).

Matters concerning marriage, divorce, paternity, legitimacy, and parentage are adjudicated according to Jewish law as determined by the rabbinical courts, unlike general laws which are legislated by Israeli parliament. For fertility analysis, rabbinical authorities permit collection of semen via coitus interruptus or by a condom with a perforation so it will not damage sperm vitality. In vitro fertilization is more nebulous, where some rabbis take a strict position and suggest that legal and biological ties are severed with oocytes (Ayensu-Corker, 2013). Overall, there is support for IVF and embryo transfer, but for Jews living outside of Israel, they are subject to laws of the country where they reside. If a gestational surrogate is used, Jewish law is much more particular with respect to motherhood, teaching that the child is related to the one who finished its formation, not who gave birth to the child (Broyde, 2010).

Islamic law endorses attempts to cure infertility and also considers it a duty (Qur'an, 23:5). The procedure of IVF is acceptable by Islam; however, it can only be practiced if it solely involves the husband and wife and is during the span of their marriage. According to Islamic law, the fusion of sperm and egg, a step beyond a sexual act (i.e., ART), cannot be intruded upon by a third party. This would desecrate the marital functions of sex and procreation. A third party gamete source is not acceptable and leads to confusion of genealogy and purity, which is of prime importance to Islam. In the context of sperm and oocyte cryopreservation outside of marriage, it is unclear (Inhorn, 2005).

The Catholic Church's views on assisted reproduction are clearly against the practice of IVF because IVF 
disregards human life and separates human procreation from sexual intercourse within marriage (Catechism of the Catholic Church). Every pregnancy must occur within a heterosexual marriage and be the result of the conjugal act between the husband and wife. Insemination, use of donor semen, IVF, surrogate motherhood, cryopreservation of embryos, and research on embryos is contrary to the unity of marriage and to the child's right to be the fruit of a holy act (CDF Donum vitae).These techniques that dissociate husband and wife cannot be morally justified and are prohibited.

Eastern Orthodox Christianity supports medical and surgical treatments of infertility. However, their church rejects IVF and other assisted reproductive techniques and opposes gamete donation on the basis that it is an adulterous act.

The Protestant Church believes that the Bible should only be the authority on religion, and religious tenets should not be shaped by tradition. Protestantism view masturbation as allowable if used as a means towards sexual self-control or as part of healthy self-exploration, but disallow it when performed with impure motives or as an addiction. The Protestant Church accepts traditional treatment of infertility; ART is partly accepted, as in the case when gametes are from a married couple and when the procedure avoids damage to the embryo. Sperm and oocyte donation are prohibited.

Hinduism places an enormous emphasis on reproduction and procreation, particularly with having a male offspring. The wife could be authorized to have intercourse with a sterile partner's brother or other family member for the purpose of having a male offspring. In the Indian society, assisted reproduction is acceptable, including sperm donation, egg and embryo donation.

Buddhism believes that laypeople can procreate in whatever manner they chooseas long as they do not harm others in concrete ways. Thus, assisted reproduction is acceptable, but donation of sperm and oocytes should be avoided as much as possible. In Japan, while sperm donation is practiced, ovum donation is prohibited.

Another component, which complicates consent and therefore may be overlooked, is the importance of religious opinion among individual family members that may vary. This may be the source of considerable conflict and lead to the decision not to pursue assisted reproductive therapies. Such conflict could lead to family discord, guilt and long-term regret. It is therefore important for all providers to be familiar with and sensitive to patients' religious and cultural beliefs and any potential reservations or familial pressure. This sensitivity may enable the provider to encourage the patient and family members to seek religious advice rather than to abandon treatment without further discussion.

Religious influences in the practice of oncofertility and fertility preservation are subtle, and clarification will undoubtedly evolve. In some religions, gamete collection and storage for fertility preservation from unmarried persons is not supported under any circumstances, including Orthodox Judaism, Islam, and Roman Catholicism. Thus, it is imperative to be sensitive and understand that the removal and storage of gametes may compromise the cancer patient's standing in the religious community, and any offspring resulting from the use of these gametes may be viewed as "illegitimate" in these religions. In some cases, special dispensation has been given when the person is married, has proven infertility, and the collection is being used for procreation. There are no such considerations for fertility preservation where there is no significant other, which is often the case in younger cancer patients.

Cryopreservation of gametes belonging to minor children involves a heterogeneous group of children and is therefore not a straightforward process. The age range may include adolescents who are entering puberty to those approaching the age of majority whose reproductive rights and choices arguably should be or may be protected as if they were adults. Differences in cultural-ethnic backgrounds and experiences also add to the complexity. As such, it is the clinician's responsibility to assist the minor patient in understanding the potential impact of cancer therapy on fertility and the options available for preserving sperm, oocytes, embryos, or ovarian tissue for future fertility. Counseling children and their families on fertility preservation therapies requires knowledge of the legalities of consent and assent. Whether the authority to make the decision to participate in therapies belongs to the parent or to the child is unclear and depends on state law and the age and maturity of the patient (Gracia, 2007).

The principles of beneficence and non-maleficence are of primary importance and hospital ethics committees may be invaluable in overseeing this aspect of the process. Failure to offer information on existing options for fertility preservation, including the risks of the procedures as well as the option not to participate, can result in medical malpractice claims against health care providers (Deepinder, 2008). It is also recognized that medical providers and hospital systems have a duty to safeguard and promote the welfare of children in their care. Safe- 
guards become particularly important in protecting pediatric patients who have been victims of sexual abuse and children whose past history of abuse has gone unrecognized. Exposure to sexual imagery for whatever purpose may further traumatize these patients and a thorough history is essential prior to such exposure.

\section{Posthumous Reproduction and Advanced Directives}

Posthumous reproduction, or reproduction after death, has historically referred to circumstances where a male partner of a pregnant woman dies after conception but before the birth of the child. This term was developed hundreds of years ago to recognize the paternity of children born to sailors while at sea. Because of advances in the science of reproduction, the definition has since expanded to include the use of assisted reproductive technologies after the demise of either the man or the woman. Successful cases of sperm extraction from a deceased man and live births have previously been reported (Shefi, 2006). There are no cases to date of posthumous oocyte extraction. In 2011, Barton et al. performed a cross-sectional survey of 1049 patients in the U.S. and found that $48 \%$ of men and $42 \%$ of women were in favor of retrieving gametes in the event of death (Quinn, 2012).

In contrast to a slightly favorable view of posthumous reproduction by the general population, physician attitudes are less favorable toward it. In 2011 Quinn et al. conducted a survey of 516 oncologists' attitudes towards posthumous reproduction in the U.S. and Puerto Rico (31). Only 16\% reported that they supported posthumous reproduction, whereas the majority did not have an opinion (51\%) or disagreed with posthumous reproduction (32\%). Despite this less than favorable stance, oncologists who were aware of ASCO guidelines for fertility preservation were more likely to discuss posthumous reproduction with patients with poor prognoses than oncologists who were not aware of guidelines. From this data, it is apparent that an understanding of the ethical and social issues surrounding posthumous reproduction remains unclear. Clarification is paramount as requests for this intervention increase with advancement in reproductive technologies.

Posthumous reproduction refers to the retrieval of gametes post mortem which are then used to create a child. Postmortem parenting (or posthumous parenting) refers to the use of gametes that are retrieved while the person is alive, but used after the persons' death. These create different ethical questions about the person's consent to retrieve or use the gametes. It also raises questions about the legal status of a child conceived postmortem. For postmortem parenting, concerns with the patient's wishes about becoming a parent after his or her demise can be obviated with advance statement of desires to parent, in a will or other testamentary document. The person is aware that the gametes are retrieved and should decide what to do with the gametes if they pass away. However, posthumous retrieval requires care and skill. By formally specifying health care preferences (through a health care directive) or designating an individual to make health care decisions (such as through a durable power of attorney for health care), patients can maintain autonomy when critically ill or at the end of life (Spoelhof, 2012). Without such a document, allowing a grieving spouse, parent or friend to grant permission to retrieve gametes has troubled morgues, hospitals and judges. Advance directive documentation is state-specific and in some states, oral statements are recognized as ethical. The Federal Patient Self-Determination Act of 1990 requires hospitals, nursing homes, and other facilities (such as ART Clinics and sperm banks) to provide information about advance directives to patients and to keep a record of any completed documentation (Doukas, 2003; Schickedanz, 2009).

Cultural, racial and ethnic factors also play a role in the completion of advance care directives. Certain ethnic groups may be less likely to complete advance directives due to mistrust of the medical system or miscommunication with medical staff; thus, they may also be more likely to request aggressive treatments until the end of life. Cultures that place an emphasis on family involvement and opinions of elders are more likely to rely on family members to make end of life decisions for them. These patients are less likely to complete advance directives (Johnson, 2008; Welsh, 2005; Ramsaroop, 2007). This becomes vitally important in the care of fertility preservation therapies where children and young adults need to make end of life decisions. Importantly, a child must be at least 18 years old to legally complete a will or advance directive. The consent process becomes complex as the patient first needs to understand his/her disease process, the prognosis of their condition, the available fertility preservation options, and finally, the implications and process of completing an advance directive. If a patient is a minor, then the law does not allow the child to make a legally binding directive, and the child's parent would be entrusted to act on behalf of the child and not act out the parent's choice if different from the child.

Cancer survivors of reproductive age are now able to live long and rewarding lives, and advancements in fertility preservation options offer increasingly realistic and optimistic futures. Fertility preservation counseling is a 
complex process that requires awareness and sensitivity to religious beliefs, bio-ethical standards, legal issues surrounding the consent/assent process, and end of life reproduction. Without appropriate and diligent attention to such concerns, the consent process is suboptimal and fertility preservation therapies cannot be equitably offered to patients. Continued awareness of available therapies and advancement of laws that promote utilization of fertility preservation therapies will improve access.

\section{Anti-Aging Insurance Policy: Healthy Young Women Freezing Their Eggs}

Women are now taking advantage of retrieving and freezing their eggs for their own use in the future. Referred to as "Fertility Insurance" and "Social Egg Freezing," women are taking steps to preserve their "young, healthy” eggs while they pursue career and other interests or for lack of a suitable partner, so that when they are ready to parent (with or without a spouse) they can be assured of their own fertility. More and more American women are waiting until they are older to have children. Many women put off childbearing to develop their professional careers, while others are waiting to find "Mr. or Ms. Right," and others still are waiting for their relationships to reach the commitment level of marriage.

Demographic trends over the past 50 years show a significant change in family development. Before the FDA approval of the contraceptive pill in 1960, the median age of marriage for women and men was 20.3 and 22.8 years respectively (Cohn, 2011; NCHS, 2010). In 2010, the median age for marriage rose to 26.1 and 28.2 years. In addition, the average age of mothers at first birth has increased from 21.4 in 1970 to 25.2 in 2009. Now, more children are born to women over age 35 than to women under age 20. For women aged 50 and over, while the actual number of births remains small (569 in 2009), this represents a five percent increase above that in 2008 and nearly 300 percent since 1997 when data for women aged 50 and over became available (Martin, 2011). It is more likely that new mothers over the age of 50 use donor oocytes, but in the future, women who previously froze their oocytes may use their own oocytes at age 35, 45 or 55. This demonstrates a significant shift not only in the perception of marriage, but also childbearing.

Extending women's fertility through egg freezing creates yet another quagmire. The same reproductive medicine techniques, which were originally used to assist infertile patients in becoming parents, can be used to push the limits of when someone becomes a parent by overcoming many hurdles, such as age or partnership status. In a recent paper on contemporary medical practice, the authors question the meaning of “advancement” and the ethics of augmenting human bodies or abilities beyond its normal state (Cristofari, 2014). By creating the ability to parent later in life, are we improving our society or will we face detrimental consequences? ART professionals and society are urged to take a step back and ask some significant questions: "Is egg freezing another form of family planning similar to that of contraception and non-therapeutic abortion?" or "Should egg freezing be celebrated as another legitimate exercise in reproductive autonomy in which technological progress reduces and ameliorates reproductive inequalities between women and men?” (Harwood, 2009). And further, "Is this reproductive technique the answer to workplace gender discrimination and pay inequity that companies and legislatures have refused to address?”

It has been implored that since men already enjoy the choice of when they have children, why shouldn't women have the opportunity to enjoy the same choices as men? (Goold, 2009). Others argue that egg freezing amounts to an illegitimate technological fix to some of the persistent problems of sexual inequality. Is "social egg freezing” an easy fix, or is, perhaps, the more correct thing to require workplace changes and high quality and affordable child care so that there is less conflict between bearing children and women's careers? The "mommy track" and a woman's career track should be synonymous. Some argue that public policy should be steered in directions that would encourage women to avoid the problem of age-related infertility simply by having children at younger ages (Bailey, 2005). The social benefits and moral arguments have been explored in favor of women and couples freezing eggs and embryos for social reasons. "Social egg freezing” promotes equal participation by women in employment; it offers women more time to choose a partner; it provides better opportunities for the child as it allows couples more time to become financially stable; it may reduce the risk of genetic and chromosomal abnormality; it allows women and couples to have another child if circumstances change; and it avoids some of the moral objections associated with freezing embryos. These views based on equal concern and respect for women suggest that women should have access to this technology despite the arguments against "fertility insurance" or "social egg freezing” (Goold, 2009).

A number of regulatory bodies, such as ASRM, and individuals continue to voice concern over the safety and 
success of this reproductive technology when used to guard against age-related infertility. ASRM argues that there are not yet sufficient data to recommend oocyte cryopreservation for the sole purpose of circumventing reproductive aging in healthy women since there are no data to support the safety, efficacy, ethics, emotional risks, and cost-effectiveness of oocyte cryopreservation for this indication. Yet this recommendation is ironic, because egg donors are healthy women exposed to the same risks, plus the additional risk of coercion and financial exploitation. The well-described risks, including infectious concerns, controlled ovarian hyperstimulation, and ultrasound-guided transvaginal egg harvest, are real but fortunately very low (Cobo, 2012; Maxwell, 2008). As seen in voluntary egg donors undergoing identical risks, the rate of serious complication (ovarian hyperstimulation requiring hospitalization, intraperitoneal bleeding, torsion, ruptured ovarian cyst, or infection) has been reported to be $0.7 \%$, and minor complaints or complications necessitating medical attention (primarily ovarian hyperstimulation not requiring hospitalization) was $8.5 \%$. Thus, is the reluctance to endorse the practice of elective oocyte cryopreservation based on safety considerations in women seeking to maximize their chances of autologous procreation appropriate, or paternalistic?

Another argument against "social egg freezing" is that physicians are offering a medical service with false hopes and expectations that only increase social pressures on women to be superwomen: super careers, super mommies, and super sexy spouses. These pressures are not concomitantly placed on men. And is it right to provide "Fertility Insurance", or "expensive confidence trick", and "contestable form of wishful medicine" (Jones, 2009; Shermers, 2009), hyped labels when the possibility of failure may be high? This particularly relates to the women more likely to seek therapy: those who are of advanced reproductive age (greater than 35 years old) and already have declining fertility due to lost ovarian quality. The biological clock relentlessly ticks away so that typically a woman's fertility (defined as probability of getting pregnant during a year) falls from 86 percent at age 20 to 52 percent at age 35, and drops even more significantly to 36 percent by age 40 , and 5 percent by age 45 (RCOG, 2011). The claim that egg freezing is a kind of "Fertility Insurance" engenders false hope in women who aim to preserve and extend their fertility. Are we overestimating the real chances of having a baby using this technique? And what about unknown risks to a relatively new IVF Process?

The limited number of randomized controlled trials and the majority of outcomes are derived from experiences using oocytes obtained from healthy, young oocyte donors under the age of 30 years. It is not clear that these data are generalizable to different patient populations including older women where outcomes decline with advancing reproductive age. A recent review of over 900 live births, of which 219 resulted from cryopreserved oocytes principally using slow-freeze technology, suggests that there is no increased risk of congenital anomalies compared to the general U.S. population (Noyes, 2009). While short-term data appear reassuring, long-term data on developmental outcomes and safety in diverse (older) populations are lacking.

And yet, many are reticent to endorse this therapy. As we sit in the "Ivory Tower" and pontificate what would be good and moral for others, some would argue that this "Fertility Insurance" constitutes more evidence of safety than was ever available before the early adoption of practices such as injection of sperm directly into eggs (ICSI) which had been employed without much testing for safety (Rybak, 2009). Indeed, the field of assisted reproduction in the United States has been criticized, perhaps justifiably, for repeatedly introducing, even promoting, laboratory breakthroughs into clinical practice without rigorous government-sponsored or supervised clinical trials to ensure safety and efficacy. Given this history of rapid acceptance of technology, adopting a cautious stance on elective egg freezing compared to previous IVF breakthroughs by various organizations with enhanced monitoring seems appropriate as this reflects a determination to better establish the safety of new techniques before their widespread use.

\section{Conclusion}

IVF has delivered on its promise to assist couples in achieving parenthood by treating infertility. In the process, it has opened the door for consideration of much broader social questions surrounding parenting and families. Cross Border Reproductive Care, oocyte donor motivations, posthumous gamete retrieval and postmortem parenting, oncofertility preservation, and fertility insurance are procedures that use IVF techniques but raise fresh legal and social questions. Some individuals who might use ART for broader purposes may resolve their moral quandaries by eliciting their religious beliefs for guidance and resolution. Others may seek legislation to ban procedures that trouble them, regardless of whether or not they are personally touched by cancer, infertility or homosexuality. 
ART technologies have been readily adapted around the world. The adoption of the technology is somewhat surprising given that there are so many nuanced social issues interwoven in its application. At the very least, ART causes societies to rethink parenting expectations and cultural norms around creating families. Since the technology is ubiquitous, countries will struggle with the inherent conflicts and challenges involved in providing medical care to treat infertility. Societies will have to decide if the unpaid donors and surrogates reduce coercion and protect the sanctity of families, or if it offers job creation and economic development, promoting gender equality and fair labor. Another global challenge is how each country will regulate or oversee ART services. Will the government see its duty to provide oversight and promote cultural policies, or will the government turn its head and allow medical or religious groups to shape access and treatment policies and their enforcement?

Discussions around safety, medical standards, and adequate legal protection for people using (or choosing not to use) ART are important. However, professional standards should not be a cloak for reinforcing a paternalistic status-quo. The challenge is both personal and global. Assisted reproduction techniques are used by professionals around the world, and they should be guided by the higher purpose of creating healthy children and happy families. Perhaps the global community, including medical professionals, social groups, families, and adult children who were conceived or born with the assistance of third parties can collaboratively work on an international foundation and guidance for global ART.

\section{References}

Adsuar, N., Zweifel, J., Pratt, E., Davidson, M., Olive, D., \& Lindheim, S. (2005). Assessment of Wishes Regarding Disposition of Oocytes and Embryo Management among Ovum Donors in an Anonymous Egg Donation Program. Fertility and Sterility, 84, 1513-1516. http://dx.doi.org/10.1016/j.fertnstert.2005.05.042

American Cancer Society (2010). Cancer Facts \& Figures 2010. Atlanta, GA: American Cancer Society.

ASRM Ethics Committee (2002). Psychological Assessment of Gamete Donors and Recipients. Fertility \& Sterility, 77, S11S12.

ASRM Ethics Committee (2005). Fertility Preservation and Reproduction in Cancer Patients. Fertility and Sterility, 83, 1622-1628. http://dx.doi.org/10.1016/j.fertnstert.2005.03.013

ASRM Ethics Committee (2007). Financial Compensation of Oocyte Donors. Fertility and Sterility, 88, 305-309. http://dx.doi.org/10.1016/j.fertnstert.2007.01.104

ASRM Ethics Committee (2013). Cross-Border Reproductive Care: A Committee Opinion. Fertility and Sterility, 100, 645650. http://dx.doi.org/10.1016/j.fertnstert.2013.02.051

ASRM Ethics Committee (2013). Recommendations for Gamete and Embryo Donation: A Committee Opinion. Fertility and Sterility, 99, 47-62.e1. http://dx.doi.org/10.1016/j.fertnstert.2012.09.037

Bailey, R. (2005). Liberation Biology: The Scientific and Moral Case for the Biotech Revolution. New York: Prometheus Books.

Banuaz-Zubair, M. (2007). Who Is a Parent? Parenthood in Islamic Ethics. Journal of Medical Ethics, 33, 605-609. http://dx.doi.org/10.1136/jme.2005.015396

Benagiano, G. (2008). Human Reproduction: Are Religions Defending the Core of Human Nature, or the Survival of Traditional Cultural Schemes? Reproductive BioMedicine Online, 17, 6-8. http://dx.doi.org/10.1016/S1472-6483(10)60324-0

Beskow, L., Botkin, J., Daly, M., Juengst, E., Lehmann, L., Merz, J., Pentz, R., Press, N., Ross, L., Sugarman, J., Susswein, L., Terry, S., Austin, M., \& Burke, W. (2004). Ethical Issues in Identifying and Recruiting Participants for Familial Genetic Research. American Journal of Medical Genetics Part A, 130, 424-431. http://dx.doi.org/10.1002/ajmg.a.30234

Biggers, J. (1978). In Vitro Fertilization, Embryo Culture and Embryo Transfer in the Human. Prepared for the Ethics Advisory Board of the United States Department of Health, Education, and Welfare, September 15.

Biggers, J. (1981). In Vitro Fertilization and Embryo Transfer in Human Beings. The New England Journal of Medicine, 304, 336-342. http://dx.doi.org/10.1056/NEJM198102053040607

Biggers, J. (2013). IVF and Embryo Transfer: Historical Origin and Development. Fertility Magazine, 15, 16-26.

Blyth, E. (2010). Fertility Patients’ Experiences of Cross-Border Reproductive Care. Fertility and Sterility, 94, e11-e15. http://dx.doi.org/10.1016/j.fertnstert.2010.01.046

Broyde, M. (2010). The Establishment of Maternity and Paternity in Jewish and American Law. Jewish Law Articles: Examining Halacha, Jewish Issues and Secular Law.

Buster, J., Bustillo, M., Thorneycroft, I., Simon, J., Boyers, S., Marshall, J., Louw, J., Seed, R. W., \& Seed, R. G. (1983). Non-Surgical Transfer of in Vivo Fertilized Donated Ova to Five Infertile Women: Report of Two Pregnancies. The Lancet, 2, 223-224. http://dx.doi.org/10.1016/S0140-6736(83)90208-8 
Bustillo, M., Buster, J., Cohen, S., Hamilton, F., Thorneycroft, I., Simon, J., Rodi, I., Boyers, S., Marshall, J., \& Louw, J. (1984). Delivery of a Healthy Infant Following Nonsurgical Ovum Transfer. Journal of the American Medical Association, 251, 889. http://dx.doi.org/10.1001/jama.1984.03340310011002

Catechism of the Catholic Church, Part Three, Section Two, Chapter Two, Article 6, III, Paragraphs 2376-2378.

Churchill, F. (1846). On the Theory and Practice of Midwifery (2nd ed.). Philadelphia, PA: Lea and Blanchard.

Cialdini, R., Cacioppo, R., Bassett, R., \& Miller, J. (1978). Low-Ball Procedure for Producing Compliance. Journal of Personality and Social Psychology, 36, 463-476. http://dx.doi.org/10.1037/0022-3514.36.5.463

Cobo, A., Bellver, J., de los Santos, M., \& Remohí, J. (2012). Viral Screening of Spent Culture Media and Liquid Nitrogen Samples of Oocytes and Embryos from Hepatitis B, Hepatitis C, and Human Immunodeficiency Virus Chronically Infected Women Undergoing in Vitro Fertilization Cycles. Fertility and Sterility, 97, 74-78. http://dx.doi.org/10.1016/j.fertnstert.2011.10.006

Cohen, I. (2010). Protecting Patients with Passports: Medical Tourism and the Patient-Protective Argument. Iowa Law Review, 95, 1467-1567.

Cohn, D., Passel, J., Wang, W., \& Livingston, G. (2011). Barely Half of US Adults Are Married-A Record Low. PewResearch Social \& Demographic Trends.

Congregation for the Doctrine of Faith (CDF) Donum Vitae II.4,5.

Cristofari, C., \& Guitton, M. J. (2014). The Steampunk Doctor: Practicing Medicine in a Mechanical Age. Advances in Anthropology, 4, 89-98.

Crooks, V., Turner, L., Synder, J., Johnston, R., \& Kingsbury, P. (2011). Promoting Medical Tourism to India: Messages, Images and the Marketing of International Patient Travel. Social Science \& Medicine, 72, 726-732.

http://dx.doi.org/10.1016/j.socscimed.2010.12.022

Crozier, G. (2010). Protecting Cross-Border Providers of Ova and Surrogacy Services? Global Social Policy, 10, $299-303$. http://dx.doi.org/10.1177/14680181100100030205

Deepinder, F., \& Agarwal, A. (2008). Technical and Ethical Challenges of Fertility Preservation in Young Cancer Patients. Reproductive Biomedicine Online, 16, 784-791. http://dx.doi.org/10.1016/S1472-6483(10)60143-5

Doukas, D., \& Hardwig, J. (2003). Using the Family Covenant in Planning End-of-Life Care: Obligations and Promises of Patients, Families, and Physicians. Journal of the American Geriatriatrics Society, 51, 1155-1158.

http://dx.doi.org/10.1046/j.1532-5415.2003.51383.x

Edwards, R. (1965). Maturation in Vitro of Human Ovarian Oocytes. The Lancet, 2, 926-929. http://dx.doi.org/10.1016/S0140-6736(65)92903-X

Edwards, R., Bavister, B., \& Steptoe, P. (1969). Early Stages of Fertilization in Vitro of Human Oocytes Matured in Vitro. Nature, 221, 632-635. http://dx.doi.org/10.1038/221632a0

Edwards, R., Steptoe, P., \& Purdy, J. (1970). Fertilization and Clevage in Vitro of Preovular Human Oocytes. Nature, 227, 1303-1307. http://dx.doi.org/10.1038/2271307a0

Goold, I., \& Savulescu, J. (2009). In Favour of Freezing Eggs for Non-Medical Reasons. Bioethics, 23, 47-58. http://dx.doi.org/10.1111/j.1467-8519.2008.00679.x

Gracia, C., \& Ginsberg, J. (2007). Fertility Risk in Pediatric and Adolescent Cancers. In T. S. K. Woodruff (Ed.), Oncofertility Preservation for Cancer Survivors (pp. 57-68). New York: Springer Verlag. http://dx.doi.org/10.1007/978-0-387-72293-1_5

Grazi, R., \& Wolowelsky, J. B. (2008). The Use of Cryopreserved Sperm and Pre-Embryos in Contemporary Jewish Law and Ethics. In: Jewish Law. http://www.jlaw.com/Articles/semen.html

Gurmankin, A. (2001). Risk Information Provided to Prospective Oocyte Donors in a Preliminary Phone Call. American Journal of Bioethics, 1, 3-15. http://dx.doi.org/10.1162/152651601317139207

Gurtin, Z. (2011). Banning Reproductive Travel: Turkey’s ART Legislation and Third Party Assisted Conception. Reproductive BioMedicine Online, 23, 555-564. http://dx.doi.org/10.1016/j.rbmo.2011.08.004

Harwood, K. (2009). Egg Freezing: A Breakthrough for Reproductive Autonomy. Bioethics, 23, 39-46. http://dx.doi.org/10.1111/j.1467-8519.2008.00680.x

Heape, W. (1891). Preliminary Note on the Transplantation and Growth of Mammalian Ova within A Uterine Foster Mother. Proceedings of the Royal Society, 48, 457-459. http://dx.doi.org/10.1098/rspl.1890.0053

Henig, R. (2004). Pandora's Baby. New York: Houghton Mifflin Company.

Homer, N., Szelinger, S., Redman, M., Duggan, D., Tembe, W., Muehling, J., Pearsoen, J., Stephan, D., Nelson, S., \& Craig, D. (2008) Resolving Individuals Contributing Trace Amounts of DNA to Highly Complex Mixtures Using High-Density SNP Genotyping Microarrays. PLoS Genet, 4, e10000167. http://dx.doi.org/10.1371/journal.pgen.1000167 
Hudson, N., Culley, L., Blyth, E., Norton, W., Rapport, F., \& Pacey, A. (2011). Cross-Border Reproductive Care: A Review of the Literature. Reproductive BioMedicine Online, 22, 673-685. http://dx.doi.org/10.1016/j.rbmo.2011.03.010

Inhorn, M., \& Gurtin, Z. (2011). Cross-Border Reproductive Care: A Future Research Agenda. Reproductive BioMedicine Online, 23, 665-676. http://dx.doi.org/10.1016/j.rbmo.2011.08.002

Inhorn, M., \& Patrizio, P. (2009). Rethinking Reproductive “Tourism” as Reproductive “Exile”. Fertility and Sterility, 92, 901-906. http://dx.doi.org/10.1016/j.fertnstert.2009.01.055

Inhorn, M., \& Patrizio, P. (2012). The Global Landscape of Cross-Border Reproductive Care: Twenty Key Findings for the New Millennium. Current Opinion in Obstetrics and Gynecology, 24, 158-163. http://dx.doi.org/10.1097/GCO.0b013e328352140a

Inhorn, M. C. (2005). Making Muslin Babies: Sunni versus Shi'a Approaches to IVF and Gamete Donation. Proceedings of the IUSSP Annual Conference, Marrakech, 15-19 July 2005.

Jaeger, A., Ross, L., \& Lindheim, S. (2012). Observed Discrepancies in Donors’ Information Sharing and Oocyte-Embryo Management and Disposition Reported To Reproductive Health Professionals: A Call for Programmatic Improvement. Journal of Bioethics Primary Research, 3, 23-32.

Johnson, K., Kuchibhatla, M., \& Tulsky, J. (2008). What Explains Racial Differences in the Use of Advance Directives and Attitudes toward Hospice Care? Journal of the American Geriatriatrics Society, 56, 1953-1958. http://dx.doi.org/10.1111/j.1532-5415.2008.01919.x

Jones, B. (2009). Lord Winston Labels Egg Freezing an “Expensive Confidence Trick”. BioNews. http://www.bionews.org/uk/page 46074.asp.

Jones, H. (2011). Seven Roads Traveled Well and Seven to Be Traveled More. Fertility and Sterility, 95, 853-856. http://dx.doi.org/10.1016/j.fertnstert.2011.01.024

Knoppers, B., \& LeBris, S. (1991). Recent Advances in Medically Assisted Conception: Legal, Ethical and Social Issues. American Journal of Law and Medicine, 17, 329-361.

Lee, S., Schover, L., Partridge, A., Patrizio, P., Wallace, W., Hagerty, K., Beck, L., Brennan, L., \& Oktay, K. (2006). American Society of Clinical Oncology Recommendations on Fertility Preservation in Cancer Patients. Journal of Clinical Oncology, 24, 2917-2931. http://dx.doi.org/10.1200/JCO.2006.06.5888

Leeton, J., King, C., \& Withers, R. (1993). The Changing Patterns of Egg Donation. Journal of Assisted Reproduction and Genetics, 10, 173-174. http://dx.doi.org/10.1007/BF01207744

Lutjen, P., Trounson, A., Leeton, J., Findlay, J., Wood, C., \& Renou, P. (1984). The Establishment and Maintenance of Pregnancy Using in Vitro Fertilization and Embryo Donation in a Patient with Primary Ovarian Failure. Nature, 307, 174175. http://dx.doi.org/10.1038/307174a0

Martin, J., Hamilton, B., Ventura, S., Osterman, M., Kirmeyer, S., Mathews, T., \& Wilson, E. (2011). Births: Final Data for 2009. National Vital Statistics Reports, 60, 1-71.

Matorras, R. (2005). Reproductive Exile versus Reproductive Tourism. Human Reproduction, 20, 3571. http://dx.doi.org/10.1093/humrep/dei223

Maxwell, K., Cholst, I., \& Rosenwaks, Z. (2008). The Incidence of Both Serious and Minor Complications in Young Women Undergoing Oocyte Donation. Fertility and Sterility, 90, 2165-2171. http://dx.doi.org/10.1016/j.fertnstert.2007.10.065

McGee, G. (1997). Subject to Payment? Journal of the American Medical Association, 278, 199-200. http://dx.doi.org/10.1001/jama.1997.03550030039018

McKelvey, A., David, A., Shenfield, F., \& Jauniaux, E. (2009). The Impact of Cross-Border Reproductive Care or "Fertility Tourism” on NHS Maternity Services. British Journal of Obstetrics and Gynaecology, 116, 1520-1523. http://dx.doi.org/10.1111/j.1471-0528.2009.02294.x

McLaughlin, L. (1982). The Pill, John Rock, and the Church. Boston, MA: Little Brown and Co.

Noyes, N., Porcu, E., \& Borini, A. (2009). Over 900 Oocyte Cryopreservation Babies Born with No Apparent Increase in Congenital Anomalies. Reproductive BioMedicine Online, 18, 769-776. http://dx.doi.org/10.1016/S1472-6483(10)60025-9

Pande, A. (2011). Transnational Commercial Surrogacy in India: Gifts for Global Sisters? Reproductive BioMedicine Online, 23, 618-625. http://dx.doi.org/10.1016/j.rbmo.2011.07.007

Pennings, G. (2004). Legal Harmonization and Reproductive Tourism in Europe. Human Reproduction, 19, $2689-2694$. http://dx.doi.org/10.1093/humrep/deh486

Practice Committee of American Society for Reproductive Medicine (2013). Fertility Preservation in Patients Undergoing Gonadotoxic Therapy or Gonadectomy: A Committee Opinion. Fertility and Sterility, 100, 1214-1223. http://dx.doi.org/10.1016/j.fertnstert.2013.08.012

Qadeer, I. (2010). Benefits and Threats of International Trade in Health: A Case of Surrogacy in India. Global Social Policy, 10, 303-305. http://dx.doi.org/10.1177/14680181100100030206 
Quinn, G., Knapp, C., Malo, T., McIntyre, J., Jacobsen, P., \& Vadaparampil, S. (2012). Physicians’ Undecided Attitudes toward Posthumous Reproduction: Fertility Preservation in Cancer Patients with a Poor Prognosis. Journal of Supportive Oncology, 10, 160-165. http://dx.doi.org/10.1016/j.suponc.2011.09.006

Ramsaroop, S., Reid, M., \& Adelman, R. (2007). Completing an Advance Directive in the Primary Care Setting: What Do We Need for Success? Journal of the American Geriatriatrics Society, 55, 277-283. http://dx.doi.org/10.1111/j.1532-5415.2007.01065.x

Rock, J., \& Menkin, M. (1944). In Vitro Fertilization and Cleavage in Human Ovarian Eggs. Science, 100, $105-107$. http://dx.doi.org/10.1126/science.100.2588.105

Rybak, E., \& Leiman, H. (2009). Egg Freezing, Procreative Liberty, and ICSI: The Double Standards Confronting Elective Self-Donation of Oocytes. Fertility and Sterility, 92, 1509-1512. http://dx.doi.org/10.1016/j.fertnstert.2009.09.008

Sauer, M. (1997). Exploitation or a Woman’s Right? British Medical Journal, 314, 1403. http://dx.doi.org/10.1136/bmj.314.7091.1403

Sauer, M., Paulson, R., \& Lobo, R. (1993). Pregnancy after Age 50: Application of Oocyte Donation to Women after the Natural Menopause. The Lancet, 341, 321-323. http://dx.doi.org/10.1016/0140-6736(93)90132-Z

Schenker, J. (1998). Oocyte Donation: Religious Perspective. In M. Sauer (Ed.), Principles in Ovum Donation (pp. 341-360). Philadelphia, PA: Springer. http://dx.doi.org/10.1007/978-1-4612-1640-7_23

Schickedanz, A., Schillinger, D., Landefeld, C., Knight, S., Williams, B., \& Sudore, R. (2009). A Clinical Framework for Improving the Advance Care Planning Process: Start with Patients' Self-Identified Barriers. Journal of the American Geriatriatrics Society, 57, 31-39. http://dx.doi.org/10.1111/j.1532-5415.2008.02093.x

Scientific Advisory Committee of the RCOG (2011). Reproductive Ageing. Royal College of Obstetricians and Gynaecologists. Scientific Impact Paper No. 24.

Shefi, S., Raviv, G., Eisenberg, M., Weissenberg, R., Jalalian, L., Levron, J., Band, G., Turek, P., \& Madgar, I. (2006). Posthumous Sperm Retrieval: Analysis of Time Interval to Harvest Sperm. Human Reproduction, 21, 2890-2893. http://dx.doi.org/10.1093/humrep/del232

Shenfield, F. (2011). Implementing a Good Practice Guide for CBRC: Perspectives from the ESHRE Cross-Border Reproductive Care Taskforce. Reproductive BioMedicine Online, 23, 657-664. http://dx.doi.org/10.1016/j.rbmo.2011.07.017

Shenfield, F., de Mouzon, J., Pennings, G., Ferraretti, A., Andersen, A., deWert, G., \& Goossens, V. (2010). The ESHRE Taskforce on Cross Border Reproductive Care: Cross Border Reproductive Care in Six European Countries. Human Reproduction, 25, 1361-1368. http://dx.doi.org/10.1093/humrep/deq057

Sleep, J. (1991). Development of International Ethical Guidelines for Epidemiological Research and Practice. Report of the Proceedings of the 25th Council for the International Organisation of Medical Sciences (CIOMS) Conference, WHO Headquarters. Geneva, Switzerland, 7-9 November 1990. Midwifery, 7, 42-44.

Society for Assisted Reproductive Technology (2012). Assisted Reproductive Technology Fertility Clinic Success Rates Report. Atlanta, GA: US Dept of Health and Human Services.

Sommezer, M., \& Oktay, K. (2006). Fertility Preservation in Young Women Undergoing Breast Cancer Therapy. Oncologist, 11, 422-434. http://dx.doi.org/10.1634/theoncologist.11-5-422

Speier, A. (2011). Brokers, Consumers and the Internet: How North American Consumers Navigate Their Infertility Journeys. Reproductive BioMedicine Online, 23, 592-599. http://dx.doi.org/10.1016/j.rbmo.2011.07.005

Spivey, W., Abramson, N., Iserson, K., MacKay, C., \& Cohen, M. (1991). Informed Consent for Biomedical Research in Acute Care Medicine. Annals of Emergency Medicine, 20, 1251-1265. http://dx.doi.org/10.1016/S0196-0644(05)81484-2

Spoelhof, G., \& Elliott, B. (2012). Implementing Advance Directives in Office Practice. American Family Physician, 85, 461-466.

Steptoe, P., \& Edwards, R. (1970). Laproscopic Recovery of Preovulatory Human Oocytes after Priing of Ovaries with Gonadotrophins. The Lancet, 1, 683-689. http://dx.doi.org/10.1016/S0140-6736(70)90923-2

Steptoe, P., \& Edwards, R. (1978). Birth after Reimplantation of a Human Embryo. The Lancet, 2, 366. http://dx.doi.org/10.1016/S0140-6736(78)92957-4

Storrow, R. (2006). Quests for Conception: Fertility Tourists, Globalization and Feminist Legal Theory. Hastings Law Journal, 57, 295-330.

The Practice Committees of ASRM and SART (2013). Mature Oocyte Cryopreservation: A Guideline. Fertility and Sterility, 99, 37-43. http://dx.doi.org/10.1016/j.fertnstert.2012.09.028

Trounson, A., Leeton, J., Besanko, M., Wood, C., \& Conti, A. (1983). Pregnancy Established in an Infertile Patient after Transfer of a Donated Embryo Fertilised in Vitro. British Medical Journal, 286, 835-838.

http://dx.doi.org/10.1136/bmj.286.6368.835 
S. R. Lindheim et al.

Wallace, W., Anderson, R., \& Irvine, D. (2005). Fertility Preservation for Young Patients with Cancer: Who Is at Risk and What Can Be Offered? The Lancet Oncology, 6, 209-218. http://dx.doi.org/10.1016/S1470-2045(05)70092-9

Whittaker, A., \& Speier, A. (2010). “Cycling Overseas”: Care, Commodification, and Stratification in Cross-Border Reproductive Travel. Medical Anthropology, 29, 363-383. http://dx.doi.org/10.1080/01459740.2010.501313

Zilberstein, M., Feingold, M., \& Seibel, M. (1997). Umbilical-Cord-Blood Banking: Lessons Learned from Gamete Donation. The Lancet, 349, 642-643. http://dx.doi.org/10.1016/S0140-6736(96)05267-1 
Scientific Research Publishing (SCIRP) is one of the largest Open Access journal publishers. It is currently publishing more than 200 open access, online, peer-reviewed journals covering a wide range of academic disciplines. SCIRP serves the worldwide academic communities and contributes to the progress and application of science with its publication.

Other selected journals from SCIRP are listed as below. Submit your manuscript to us via either submit@scirp.org or Online Submission Portal.
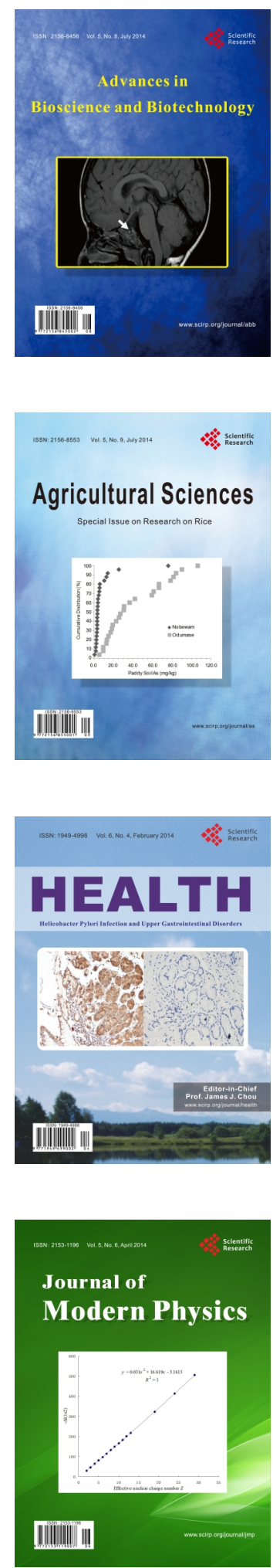
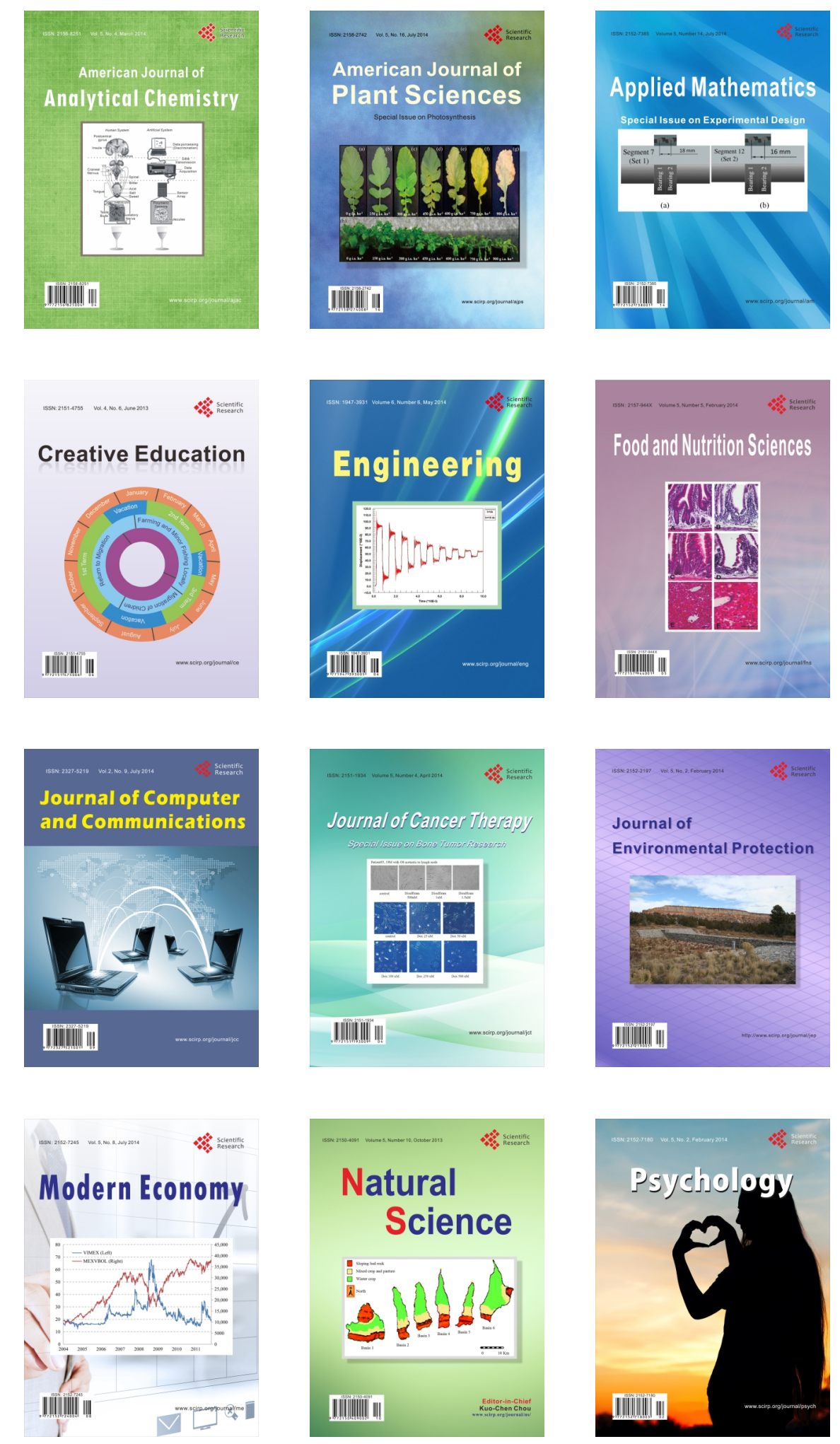